\title{
obituary
}

\section{J. N. Mills}

John Norton Mills, Brackenbury Professor of Physiology at Manchester University, died in a tragic climbing accident in Snowdonia on 3 December 1977, at the age of 63 . Born into a medical family, he was educated at Winchester and Oxford, and graduated in medicine at Birmingham in 1939. Following a brief interlude in general practice, his personality and talents directed him back to the more congenial cloisters of Oxbridge. After a Lectureship at New College, Oxford (1941-46), and a Lectureship and Fellowship at Jesus College, Cambridge (1946-1950), he departed for Manchester, as Lecturer in Human Physiology, where he spent the rest of his working life. Promoted Senior Lecturer in 1955 and Reader in 1959, he was appointed to the Brackenbury chair in 1965.

At Manchester, his earlier interests in respiration and the kidney converged into a wide programme of work on the components and mechanisms relating to human circadian rhythms and the 'internal clock'. In addition to a wealth of observations concerning the changes in rhythms associated with jettravel, shift-work, and cavers living in isolation for extended periods-all of interest to the popular media-the establishment of an 'isolation unit' at Risley enabled John Mills and his colleagues to perform careful studies on humans living in experimental, controlled isolation. Fortunately, a series of definitive papers prepared during a sabbatical year, 1976-77, is now in press.

In the field of human chronobiology his contributions to books and journals were extensive; and from his position as a highly respected world authority, he was particularly involved in the activities of chronobiological journals and societies. From his deep interest and skills in field botany and climbing, the Linnean Society and various climbing clubs have known his writings. And the Physiological Society, Renal Association and Journal of Physiology have all benefited from his participation.

At Manchester, he was an early, effective campaigner for broadening representation on university bodies, and for the associated revision of the University Charter. His tenure as a founding co-editor of the university staff magazine was noted by brave encouragement (and, occasionally, pseudonymous authorship) of humor- ous, satirical, occasionally scandalous articles, in the best polemical tradition, causing delight or offence in the reader according to personal opinions and prejudices. His occupancy of the Brackenbury chair was associated with the planning and development of the new medical school, and with the transformation of a small dilapidated department into one of the largest and best-equipped in Britain. After such a revolutionary period of change in structure and attitudes, he might have looked forward to a period of consolidation, and a strengthening of those aspects of the university in which he believed deeply-as a community of equals, providing education, culture and the base for research and academic freedom.

As a sincere Christian, personally involved in Church activities, John Mills showed warmth, kindness, and an understanding toleration of dissenting views in others. His personality was most evident in the small-group setting -tutorials, seminar, graduation, scientific meeting-where his pleasure in wine, bridge, climbing, botany, conversation and intellectual challenge would become readily apparent. In the best traditions of British human physiologists, his personal example induced a host of volunteers into a succession of potentially hazardous procedures, which seemed to be cheerfully tolerated by the subjects-if not by the alarmed dependents.

His death, within a few days of a definite decision to retire at 65 , seems the more cruel and premature; but in the mountains he loved and after the successful completion of a challenging climb, perhaps the sense of tragedy may be alleviated.

\section{S. Thomas}

\section{W. Ottaway}

Christopher Wyndham Ottaway, Emeritus Professor of Veterinary Science in the University of Bristol, died on 14 February 1978 at the age of 67. He had occupied the chair of Veterinary Anatomy in the University from 1949-73, his being the second professorial appointment from the start of the School of Veterinary Science.

He qualified at the Royal Veterinary College, London and returned to join the staff of the Anatomy Department there in 1934, becoming a Reader in 1943. In the same year he was awarded a Fellowship of the Royal College of Veterinary Surgeons for a thesis on The anatomical closure of the foramen ovale in the equine and bovine heart: a comparative study with observations on the foetal and adult states.

In 1945 Christopher Ottaway moved with a Senior Wellcome Research Fellowship to work in the Department of Zoology of Cambridge University under the late Professor Sir James Gray. There, while a member of King's College, he was able to develop his great interest in the functional anatomy of locomotion in animals and in 1948 he was awarded a Ph.D for a thesis in this field with special reference to the fore-limb of the dog. In the same year he was appointed to a lectureship in the Department of Zoology.

During this period, after publication of the Loveday Committee's second report on Veterinary Education in Great Britain, this topic was under continual debate. Christopher Ottaway was an active protagonist in support of the Committee's conclusion that all veterinary education should be within universities, a not too popular view at that time, either in universities or the veterinary profession.

It was fitting, therefore, that he was an early recruit to the staff of one of the two completely new universitybased schools that resulted once Loveday's recommendations were put into operation. His appointment to the chair of Veterinary Anatomy at Bristol in 1949 meant that he was deeply involved in the development of the school from the start but at the same time he was able to continue his work related to locomotion and movement in animals.

He contributed a chapter on 'The Mechanism of Movement' in Hammond's Progress in the Physiology of Farm Animals (Vol. II, Butterworths, London, 1955). In 1961 he used as his title 'The Anatomy of Motion' in giving the Share Jones Memorial Lecture of the Royal College of Veterinary Surgeons (Vet. Rec. 74, $279-285,1962$ ). He had for many years been an admirer of the 18th century painter George Stubbs and he collaborated with the late Professor James McCunn in providing a commentary for the 1965 edition of Stubb's 1776 work The Anatomy of the Horse (J. A. Allen \& Co. Ltd., London).

Stimulated by his interest the Bristol group of veterinary anatomists, together with a succession of postgraduate researchers, have contributed widely to the knowledge of locomotion, movement and related fields, and the 